\title{
Modeling optimal oil production paths under risk service contracts
}

\author{
Luo Dongkun and $\mathrm{Zhao} \mathrm{Xu}^{*}$ \\ School of Business Administration, China University of Petroleum, Beijing 102249, China \\ (C) China University of Petroleum (Beijing) and Springer-Verlag Berlin Heidelberg 2013
}

\begin{abstract}
Due to the rigorous fiscal terms and huge potential risk of risk service contracts, optimizing oil production paths is one of the main challenges in designing oilfield development plans. In this paper, an oil production path optimization model is developed to maximize economic benefits within constraints of technology factors and oil contracts. This analysis describes the effects of risk service contract terms on parameters of inputs and outputs and quantifies the relationships between production and production time, revenues, investment and costs. An oil service development and production project is illustrated in which the optimal production path under its own geological conditions and contract terms is calculated. The influences of oil price, service fees per barrel and operating costs on the optimal production have been examined by sensitivity analysis. The results show that the oil price has the largest impact on the optimal production, which is negatively related to oil price and positively related to service fees per barrel and operating costs.
\end{abstract}

Key words: Risk service contract, optimal production path, nonlinear programming, service fees per barrel, sensitivity analysis

\section{Introduction}

An oil contract and its fiscal terms are the legal documents of a host country government and they determine the control level of the government on oil resources and how to distribute the benefits between the government and international oil companies (IOC) (Zhou and Zheng, 2006). Oil contracts reflect the international oil cooperation modes. Royalty/tax contracts, production sharing contracts and risk service contracts are widely used worldwide (Daniel, 1994). Although the countries and areas using risk service contracts are much less than those using royalty/tax contracts and production sharing contracts in volume terms, the risk service contracts are mainly used in the oil producing countries with very large reserves in the Middle East and South America. The number of countries using risk service contracts has been increasing in recent years, especially after 2008, Iraq and Ecuador etc. abandoned previous production sharing contracts and turned to risk service contracts, thus this mode of contact is gradually preferred by host countries (Guo et al, 2010). The most important features of risk service contracts are that the governments of host countries own the exclusive operating rights on the contractual block and selling rights for the produced crude oil. However, the IOC provides all the funds and technical services in the process of exploration, development and production and bears all the

*Corresponding author. email: zx_1210d@hotmail.com

Received June 22, 2013 risks. Meanwhile, the IOC recovers the costs from the sales revenue and obtains service fees in an agreed proportion (Wang, 2007). Rigorous fiscal terms, high bonuses, service fee ceilings, government participation, and service fees controlled by $R$ factors (Accrued net earnings/Accrued total expenditure) and performance factors, limit the income level and excess return to the IOC caused by increases of output and oil price (Wood Mackenzie, 2010). The potential risks and benefits for IOC are unequal under risk service contracts. Therefore in this paper, we investigate optimal production paths to maximize the returns for the IOC, which is helpful to increase the investment benefits and reduce risks.

Along with the risk service contracts being commonly used in Iraq and countries in South America, scholars are paying more attention to this type of contract. Guo and Han (2009) analyzed the change from production sharing contracts to risk service contracts in Iraq in the last twenty years, and compared the characteristics of the two types of contracts. Hao et al (2011) studied risk service contracts and the revenues distribution system in Iraq. Liu et al (2012) investigated the nationalization of oil resources in Ecuador, and analyzed its risk service contract. Su and $\mathrm{Yu}(2012)$ described the investment environment in Venezuela, and analyzed the service contracts for old oilfields and marginal fields. Ebrahimi and Khouzani (2003) made a comparison between service contracts and buy-back contracts. Reiter and Bolling (2000) discussed the influences of production sharing contracts and risk service contracts on reserves reporting.

For production optimization, Rao (2000) established 
a dynamic non-linear programming (NLP) model with minimum discounted present value of overall economic cost as the objective, and applied it in upstream investment in India and finally obtained the optimal production programming. Ravagnani et al (2012) developed the optimal extraction strategies under royalty/tax contracts and production sharing contracts in Brazil, and got the optimal well numbers, production and contractor takes. Helmi-Oskoui et al (1992) derived the profit maximizing time-path of joint production of oil and gas to determine optimal extraction rates using average reservoir data as well as expected prices and costs. Gao et al (2009) modeled the economically optimal dynamic oil production decisions for a stylized oilfield resembling the largest developed field in Saudi Arabia based on the functions of fluid pressure, formation characteristics, water injection, new wells etc.

In this paper, we design an optimal production path on the basis of oil exploitation and economic rules with restriction of risk service contracts. This procedure quantifies the relationship between production and input-output parameters. A method for prediction of production in the decline phase via production rate and stable periods is developed. Meanwhile, the influence of oil price, service fees per barrel and operating costs on the optimal production is examined.

\section{Analysis of influence factors}

Production optimization under risk service contracts is affected by three factors: innate geological conditions of the oil reservoir, technology factors and oil contracts. The geological factors of oil reservoirs consist of the structural features, distribution and physical properties, fluid properties and types, etc. (Yu and Li, 1998). They are the foundation for preparation of an oilfield development plan, because the plan taken in programming and used for reservoir development to some extent reflects the accumulated development experience of reservoirs with similar geological features ( $\mathrm{Li}$ et al, 2005).

The technological factors include development scheme, partition and combination of layer series, well patterns and spacing, drilling and production technology and water injection method etc. They play essential roles in optimizing inputs and outputs of development projects. Among the technology factors, well spacing density is the key factor which influences production. The denser the well patterns, the more the production wells are, and the higher the control degree of water flooding is, and thus, a higher production can be obtained. But when the number of wells is excessive, the recoverable reserves controlled by one single well will decrease, and the development cost of oil per barrel will significantly increase. Finally, the economic benefits will decrease instead (Li, 2006).

The oil contract is the legal basis which defines the rights and obligations among parties to the contract in exploration and production, and the criterion for capital expenditure and income distribution. The effect of oil contracts on the benefits of contractors varies with different production paths. Since the fiscal terms like taxes and service fees etc. are determined by sliding scales in risk service contracts, production variation will make the sliding scales step in different tranches.
Correspondingly, the expense disbursement and service revenues will change, so does the net present value (NPV). Even for the same contract type, the specific terms in different countries will vary. But all the issues can be summarized as who provides the funds and how to distribute the profits (Luo and Yan, 2010). Consequently, the economic target of production optimization under risk service contracts does not depend on the type of contract or one particular term, but on the combined effects of contract terms.

\section{Approach}

Obtaining an optimal oil production path is an optimization control process, in which the influence of technical measures and contract terms on inputs and outputs of the project should be comprehensively considered, and the maximum economic benefit should be regarded as the goal for preparing a reasonable production plan for the contract duration. The dynamic nonlinear programming model is established with the maximum net present value (NPV) for the IOC being set as the objective function, engineering technical measures and contract terms as linear or non-linear constraints. The NPV model is composed of cash inflow and outflow of IOC, which are optimized with the production as a variable. So the functions between production and revenues, investment and costs should be constructed.

\subsection{Revenues function}

The revenues of the IOC consist of cost recovery and service fees under risk service contracts. The cost recovery ceiling is set based on a percentage of total revenues, and unrecovered costs can be carried forward and the excess cost recovery forms the profits of National oil company (NOC). The service fees are computed from the product of production or incremental production, and the bidding parameterservice fees per barrel, which changes with the sliding scales including $R$ factor, production, accumulated production etc. The revenues of the IOC are calculated as Eq. (1),

$$
R_{c}=q_{t} \cdot R F B_{R} \cdot x+C_{r}
$$

where $R_{c}$ denotes the revenues of IOC; $q_{t}$ is the production at the year " $t$ "; $R F B_{R}$ represents the service fees per barrel; $x$ is the participation rate of IOC; $C_{r}$ represents the recoverable costs, consisting of operating costs, capitalized costs such as exploration, development investment and other costs.

Every oilfield has a unique production profile, but its production has to go through a build-up, plateau production and decline phase (Bradley and Wood, 1994). Production in build-up and plateau phases depends on the designed capacity, which is determined by proved geological reserves and production rate; production in the decline phase is related to production on the plateau and the decline rate (Poston and Poe, 2008; Ruth and Cleveland, 1993). The higher the production on the plateau, the bigger the decline rate is and the shorter the plateau production period is, and vice versa. The formulation on relationship between peak production and production in the decline phase can be deduced from the primitive method of the Weng model (Fan et al, 2007; Weng, 
1984),

$$
q_{t}=\left\{\begin{array}{l}
N \cdot V \cdot \frac{t}{T_{1}}, t \in T_{1} ; \\
N \cdot V, t \in T_{2} ; \\
N \cdot V \cdot \frac{1}{12} \cdot \sum_{k=1}^{12}\left[a \cdot t_{(i-1) \times 12+k}^{b} \cdot \mathrm{e}^{-c c t_{(i-1) \times 12+k}}\right], t \in T_{3}
\end{array}\right.
$$

where $N$ denotes the proved geological reserves; $V$ is the production rate in the plateau phase; $T_{1}$ is the build-up phase; $T_{2}$ is the plateau phase; $T_{3}$ is the decline phase; $t_{(i-1) \times 12+k}$ represents the decline phase, month; $i$ is the forecast time, in which $i=1$ means the first year and $i=2$ means the second year and so on; $a, b, c$ are the coefficients of this declining production forecast model.

The decline rate of base oil is specified in risk service contracts, in which the service fees are calculated based on incremental production. And the yield at this decline rate can be achieved by normal operation of the NOC. So the incremental production equals to total production minus the basic oil.

$$
\Delta q_{t}=q_{t}-q_{0} \cdot\left(1-D_{0}\right)^{t}
$$

with $\Delta q_{t}$ the incremental production at the year " $t$ "; $q_{0}$ the production in plateau with the basic well pattern; $D_{0}$ the decline rate of base oil.

For a developed oilfield with a basic well pattern, the incremental production is obtained from increasing the well density and adjustment, which can increase recoverable reserves or production rate, with a single effect or two superimposing effects (Yang and Zhang, 2006). Adding recoverable reserves means enhancing oil recovery, and increasing production rate only accelerates the development (Fig.1). In general, the purpose of oil service projects paid on incremental production is to enhance oil recovery, so the effect of adding recoverable reserves should be included.

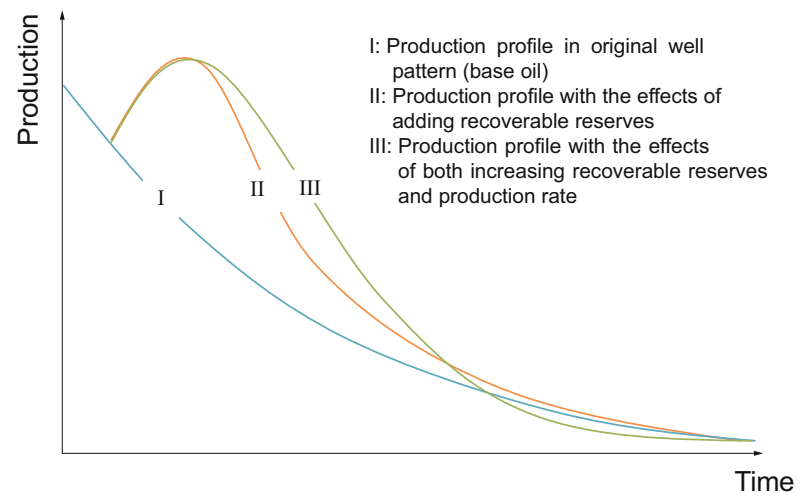

Fig. 1 Schematic illustration of production profiles with increasing well numbers and adjustment

The incremental production with the effect of adding recoverable reserves forms new production decline curves,

$$
q_{t}{ }^{\prime}=\Delta N \cdot V^{\prime} \cdot \frac{1}{12} \cdot \sum_{k=1}^{12}\left[a \cdot t_{(i-1) \times 12+k}^{b} \cdot \mathrm{e}^{-c V^{\prime} t_{(i-1) \times 12+k}}\right]
$$

where $\Delta N$ represents the incremental reserves; $q_{t}^{\prime}$ denotes the incremental production at the year " $t$ "; $V$ is the production rate of incremental reserves.

For the incremental production with the effects of increasing recoverable reserves and production rate, the new production in decline is shown as Eq. (5),

$$
q_{t}{ }^{\prime \prime}=(N+\Delta N) \cdot V^{\prime \prime} \cdot \frac{1}{12} \cdot \sum_{k=1}^{12}\left[a \cdot t_{(i-1) \times 12+k}^{b} \cdot \mathrm{e}^{-c V^{\prime \prime} t_{(i-1) \times 12+k}}\right]
$$

with $q_{t}$ " the total annual production at the year " $t$ "; $V$ " the new production rate.

\subsection{Investment function}

An oilfield with bigger production capacity means that the initial well spacing density is denser, and the adjustment scope in the later period is smaller, and also the times of densification are less, and vice versa (Solow and Wan, 1976).

The development investment includes the investment in production wells and ground engineering. The investment in production wells is equal to the well numbers multiplied by the investment per well, which can be calculated as the quotient of annual production per well divided by the product of geological reserves and production rate. The ground engineering includes gathering and transportation, water injection and matching construction. The investments in gathering and transportation, water injection and power supply etc. are related to the capacity, which can be calculated by the product of unit capacity investment quota and the capacity. The investment of road construction etc. unrelated to the capacity is constant.

$$
I_{t}=\left(\frac{i_{d} \cdot\left(1+k_{z}\right)}{t_{\alpha} \cdot q_{0}}+i_{g}\right) \cdot N \cdot V+I_{g 0}
$$

where $I_{t}$ denotes the development investment at the year " $t$ "; $k_{z}$ is the injector-producer ratio; $i_{d}$ represents the average investment in a single production well; $t_{\alpha}$ is the number of producing days in one year; $q_{0}$ denotes average stable daily production per well; $i_{g}$ is the unit capacity investment; $I_{g 0}$ represents the fixed investment.

Due to the fact that the primary ground construction can be used for incremental production capacity, the new investment is for the capacity that exceeds the original, and the incremental investment only includes that related to the additional capacity.

$$
I_{t}{ }^{\prime}=\left(\frac{i_{d} \cdot\left(1+k_{z}{ }^{\prime}\right)}{t_{\alpha} \cdot q_{0}}+i_{g}\right) \cdot \Delta N \cdot V^{\prime}
$$

where $I_{t}^{\prime}$ is the incremental development investment; $K_{z}$ denotes the new injector-producer ratio.

\subsection{Operating cost function}

The operating cost is incurred over the process of operating and maintaining various kinds of oil and gas wells as well as related equipment facilities, and it synthetically reflects the resource quality, level of exploration and 
development, effectiveness of technology and operating management (Kaiser, 2006). The operating cost can be predicted by the cost driver method, in which the cost drivers mainly include oil well numbers and oil production, and the fee quota can be determined referring to the cost data of the same or similar blocks, taking into account the factors like location, exploitation method, ground processes, physical properties of reservoir, and single well production etc. (Luo and Zhao, 2012). The prediction model of the operating cost can be written as:

$$
C_{t}=c_{q} \cdot q_{t}+c_{n} \cdot n_{t}
$$

where $C_{t}$ is the annual operating cost at the year " $t$ "; $c_{n}$ represents the operating cost of single well; $c_{q}$ denotes the operating cost per unit of oil production; $n_{t}$ is the number of wells at year " $t$ ".

The operating cost of a single well includes labor expense, material and fuel cost, downhole operating cost, well logging and testing cost per well. The operating cost per unit of production consists of light ends fee, transportation cost, and oil processing fee etc. (Ge and Guo, 2004).

\subsection{Economic limits}

After the well spacing is reduced, the production rate will increase, and the production will decline faster, so the oilfield will reach its economic limit sooner. Therefore, the production threshold should be in the optimization model as a constraint.

Since reserves deplete and difficulty of exploitation increases in the later period, revenues may not recover costs under continued operation, so overall benefits will deteriorate. The economic limit of an oilfield is defined as the time when the operating cost of the oilfield is equal to the income under production (Kaiser and $\mathrm{Yu}, 2010$ ). It is assumed that an oilfield will cease production at its economic limit, and thus, the economic limit is determined as:

$$
C_{t}=q_{t} \cdot p \cdot f
$$

The production threshold is:

$$
q_{t}=\frac{c_{n} \cdot n_{t}}{c_{q}-p \cdot f}
$$

\subsection{Production optimization model}

The IOC needs to search for the optimal production path to maximize the dynamic benefits- NPV in the contract duration. According to the forecasting methods above, both the input and output parameters of the IOC are expressed as functions of oil production. The optimization model is established as follows:

$$
\begin{aligned}
& \operatorname{Max}_{N P V\left(q_{t}\right)}\left\{\sum_{t=0}^{T}\left(R_{t}-C_{t}-T A X_{t}-R_{g t}\right) \times\left(1+i_{0}\right)^{-t}-I_{t} \times\left(1+i_{0}\right)^{-t}\right\} \\
& \text { s.t. } \quad 0<q_{t} \leq q_{\max } \cdot t_{\alpha} \\
& \qquad q_{t} \geq \frac{c_{n} \cdot n_{t}}{c_{q}-p \cdot f} \\
& \quad N>0
\end{aligned}
$$

where $T A X_{t}$ is the income tax at the year " $t$ ", which is levied on a proportion of service fees; $i_{0}$ denotes the benchmark discounted rate. The host country defines the production ceiling of each block in the oil contract to prevent destructive exploitation. So the production in the plateau phase should be less than the production ceiling, where $q_{\max }$ is the ceiling of daily production provided in the contract. The production in the decline phase should be higher than the production threshold. Meanwhile, the geological reserves should be more than 0 . Consequently, the production sequence here is the optimal production path.

\section{Application}

This paper takes as an example of oil development projects in Iraq for which service development and production contracts (SDPC) were signed. The contract duration is 20 years. The government participates in 25 percent, and IOC takes 75 percent. IOC provides the total funds for development and production, and recovers costs and gets service fees from sales. The signature bonus is 1 million dollars. Half of the sales revenues are paid for service and the other belong to the government. If the half of the revenues is less than the sum of recoverable costs and service fees, unrecoverable costs and unpaid service fees can be carried forward without interest; if the former is more than the latter, the surplus belongs to the government. The service fees are distributed between government and IOC according to $R$ factor in Tablel, and that belonging to IOC is subject to income taxes at 35 percent rate. Other parameters are shown in Table 2.

Table 1 Sliding scale $R$ factor for service fees

\begin{tabular}{cc}
\hline$R$ factor & Service fees per barrel, USD \\
\hline$<1.0$ & $\mathrm{RFB}$ \\
$1.0-1.25$ & $80 \% \times \mathrm{RFB}$ \\
$1.25-1.5$ & $60 \% \times \mathrm{RFB}$ \\
$1.5-2.0$ & $50 \% \times \mathrm{RFB}$ \\
$>2.0$ & $30 \% \times \mathrm{RFB}$ \\
\hline
\end{tabular}


Table 2 Some parameters used for this example

\begin{tabular}{|c|c|c|}
\hline Parameters & Values & Units \\
\hline Proved geological reserves $N$ & $900 \times 10^{6}$ & Barrels \\
\hline Operating cost of single well $c_{n}$ & 20 & Dollars/well \\
\hline Fixed investment of ground engineering $I_{g 0}$ & $50 \times 10^{6}$ & Dollars \\
\hline Single well investment $i_{k}$ & $3 \times 10^{6}$ & Dollars/well \\
\hline Injector-producer ratio $k_{z}$ & $1: 1$ & --- \\
\hline Income tax rate $\operatorname{tax}$ & 35 & $\%$ \\
\hline Oil price $p$ & 60 & Dollars/barrel \\
\hline Discount rate $i_{0}$ & 10 & $\%$ \\
\hline
\end{tabular}

$R$ factor $=$ Accrued net earnings/Accrued total expenditure, where accrued net earnings include accrued cost recovery and service fees of the IOC, and the accrued total expenditure means the costs consisting of development investment and operating costs etc.

The annual production in the decline phase can be predicted by the Weng model, in which the parameters are estimated by analogy with data from similar fields.

$$
q_{t}=N \cdot V \cdot \frac{1}{12} \cdot \sum_{k=1}^{12} 0.985 \cdot t_{(i-1) \times 12+k}^{-0.075} \cdot \mathrm{e}^{-0.3 V \cdot t_{(i-1) \times 12+k}}
$$

The incremental proven geological reserves are $1 \times 10^{8}$ barrels, and the incremental reserves were put into production at the end of the initial plateau phase. The extreme value of production rate is calculated as $2.45 \%$. Therefore, within constraints of the ceiling production and production threshold, the optimal production rate is $2.45 \%$, and NPV is $2.039 \times 10^{9}$ dollars (Fig. 2).

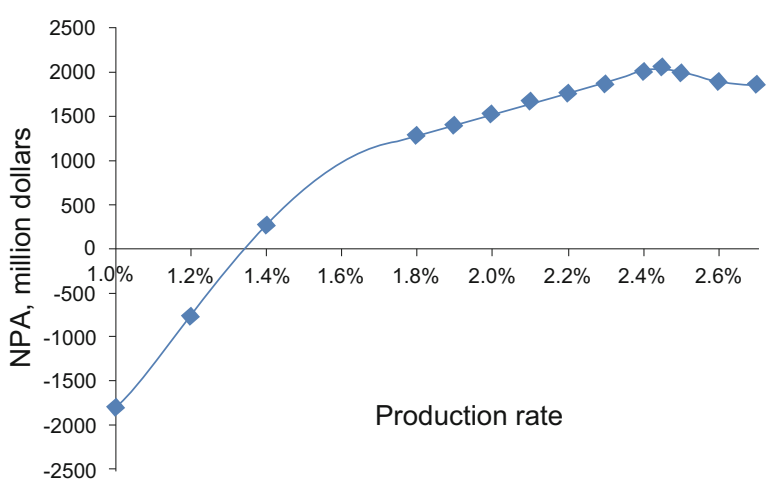

Fig. 2 Change of NPV at different production rates

Oil price, operating cost and service fees per barrel are the sensitive variables in the optimization model. Sensitivity analysis is introduced to describe the influence of changes of each factor on the optimal production. A sensitivity analysis was performed to determine the main factors causing the most variability in the model. The procedure is to calculate the benchmark value of each input variable, and then to change, respectively, the benchmark value of each input variable by $10 \%,-10 \%$ when the other input variables are kept unchanged, and then to study how the optimal production changes with the changes in each input variable (Fig. 3) (Fu and Tong, 2005). As can be seen, oil price is the most sensitive variable, and has negative effects on optimal production, that is to say, the optimal production decreases as the price increases. The operating costs and service fees per barrel throw positive impacts on the optimal production.

Oil price, service fees per barrel and operating costs, which are changed by $10 \%$ and $-10 \%$, are plugged into the model to get the optimal production rate and the maximum NPV, referring to Fig. 4. As we can see, oil price is negatively related to the optimal production rate and its corresponding $\mathrm{NPV}$, and as oil price increases, the optimal production rate decreases so does the NPV; service fees per barrel and operating costs are positively correlated to the optimal production rate and NPV.

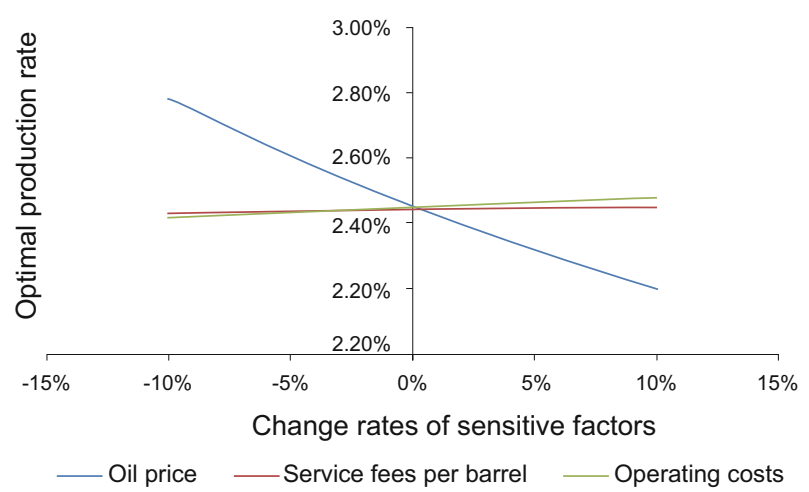

Fig. 3 Influences of sensitive factors on the optimal production 


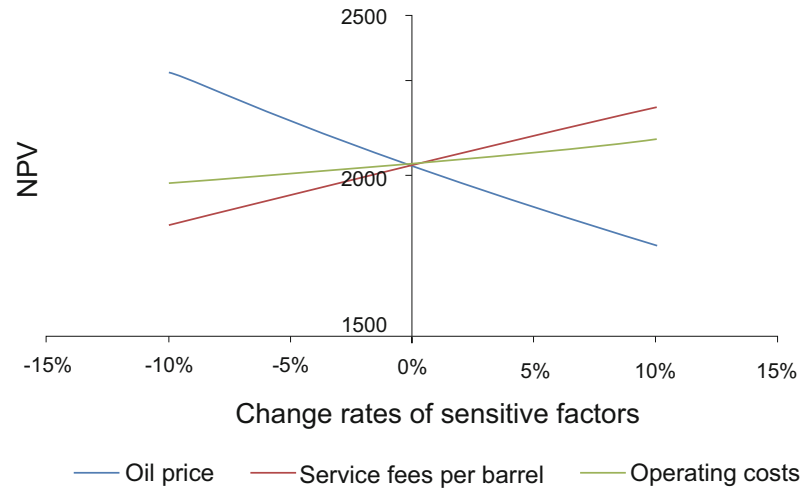

Fig. 4 Influences of sensitive factors on corresponding NPV of optimal production

\section{Conclusions}

In this paper, taking characteristics of risk service contracts into account, a model for deciding the optimal production path for an oil field has been developed. The description of the influence of risk service contract terms on input and output parameters and the analysis of the relationship among production and production time, revenues, investment and costs are absorbed in this model. This study analyses the impact of the variation of production in the whole oilfield lifecycle on economic benefits, integrally optimizes the inputs and outputs of oilfield development project, which can avoid the deviation resulting from simply calculating the economic benefits at a certain stage.

The service development and production project in Iraq is illustrated for example, and the optimal production path under its resource condition and contract terms has been calculated. The influences of oil price, service fees per barrel and operating costs on the optimal production have been examined by sensitivity analysis. The results show that the oil price has the most impact on the optimal production, and the optimal production is negatively related to oil price and positively related to service fees per barrel and operating costs. The analysis of the relationship between contract terms and production in this paper is very helpful for companies to negotiate some elastic terms in this type of contracts. Simultaneously, the research on production paths provides crucial information for companies to choose development strategies and rationalize distribution of resources.

\section{Acknowledgements}

Funding for this work was provided by the Major Project from the National Social Science Foundation of China through research on replacement strategies for overseas oil and gas resources based on the perspective of China's petroleum security under the project number 11\&ZD164. We wish to thank the anonymous reviewers of this manuscript for their elaborate work.

\section{References}

Bradley M E and Wood A R O. Forecasting oilfield economic performance. Journal of Petroleum Technology. 1994. 46(11): 965971
Daniel J. International Petroleum Fiscal Systems and Production Sharing Contracts. Tulsa: PennWell Books. 1994

Ebrahimi S N and Khouzani S A. The contractual form of Iran's buyback contracts in comparison with production sharing and service contract. SPE 81547 presented at 13th Middle East Oil Show \& Conference held in Bahrain, 9-12 June 2003

Fan J W, He D, Liu F, et al. Research on relationship of rate of oil production with stable production period and decline rate in fresh developing zone. Fault-Block Oil and Gas Field. 2007. 14(4): 47-48 (in Chinese)

Fu J J and Tong Y H. Technical Economics of Industry. Beijing: The Press of Tsinghua University. 2005 (in Chinese)

Gao W Y, Hartley R P and Sickles C R. Optimal dynamic production from a large oil field in Saudi Arabia. Empirical Economics. 2009. 37(1): 153-184

Ge A J and Guo P. Theory and Practice of International Oil and Gas Cooperation. Beijing: Petroleum Industry Press. 2004 (in Chinese)

Guo J Y, Zhang S, Bao J C, et al. Reflections on CNPC winning the bid for service contracts of Iraqi oil fields. Journal of Southwest Petroleum University (Social Science Edition). 2010. 3(5): 13-16 (in Chinese)

Guo P and Han T. Policy change of oil cooperation in Iraq from the view of contract change. International Economic Cooperation. 2009. (4): 64-68 (in Chinese)

Hao H, Wang P and Wang Z. Analysis of contract mode and fiscal terms for oil cooperation in Iraq. Friends of Accounting. 2011. (22): 106108 (in Chinese)

Helmi-Oskoui B, Narayanan R, Glover T, et al. Optimal extraction of petroleum resources: an empirical approach. Resources and Energy. 1992. 14(3): 267-285

Kaiser M J. Hydrocarbon production cost functions in the Gulf of Mexico. Energy. 2006. 31(12): 1726-1747

Kaiser M J and Yu Y K. Economic limit of field production in Texas. Applied Energy. 2010. 87(10): 3235-3254

Li J. The Choice and Appraisal of Reservoir Exploration Rates in China. Doctoral thesis from Yanshan University. 2006. 16-18 (in Chinese)

Li L M, Du Z M, Du J, et al. The study of a reasonable oil recovery rate model for a fracture-VUG type carbonate reservoir in the early development period. Journal of Southwest Petroleum Institute. 2005. 27(5): 29-32 (in Chinese)

Liu H B, Zhou J S, Chen H, et al. Ecuador's oil policy changes in recent years and the main features of risk-service contracts. International Petroleum Economics. 2012. (3): 40-44 (in Chinese)

Luo D K and Yan N. Assessment of fiscal terms of international petroleum contracts. Petroleum Exploration and Development. 2010. 37(6): 756-761

Luo D K and Zhao X. Modeling the operating costs for petroleum exploration and development projects. Energy. 2012. 40(1): 189-195

Poston S W and Poe Jr B D. Analysis of production decline curves. Richardson. TX: Society of Petroleum Engineers. 2008

Rao R D. An integrated modeling framework for exploration and extraction of petroleum resources. Resources Policy. 2000. 26(3): 133-143

Ravagnani G A T F S, Lima C G A, Barreto C E A G, et al. Comparative analysis of optimal oil production strategy using royalty $\&$ tax and production sharing petroleum fiscal models. SPE 150907 presented at the North Africa technical conference and exhibition held in Cairo, Egypt, 20-22 February 2012

Reiter D F and Bolling J D. Comparison of booking methodologies for production sharing agreements and service contracts. SPE 63203 presented at the 2000 SPE Annual Technical Conference and Exhibition held in Dallas, Texas, 1-4 October 2000

Ruth M and Cleveland C J. Nonlinear dynamic simulation of optimal 
depletion of crude oil in the lower 48 United States. Computers, Environment and Urban Systems. 1993. 17(5): 425-435

Solow R M and Wan F Y. Extraction costs in the theory of exhaustible resources. The Bell Journal of Economics. 1976. 7(2): 359-370

$\mathrm{Su} \mathrm{W}$ and $\mathrm{Yu} \mathrm{Z} \mathrm{W.} \mathrm{A} \mathrm{comprehensive} \mathrm{evaluation} \mathrm{of} \mathrm{investment} \mathrm{on}$ Venezuelan oil and gas resources. Sino-Global Energy. 2012. 15(10): 12-16 (in Chinese)

Wang N P. Comparison and research in international petroleum contract modes. Doctoral thesis from University of International Business and Economics. 2007. 51-52 (in Chinese)

Weng W B. The Foundation of the Forecasting Theory. Beijing: Petroleum Industry Press.1984 (in Chinese)
Wood Mackenzie. Rumaila award rescues Iraq's first licensing round [R/ OL]. [2010- 04- 05]. http: / /www.woodmackenzie.com

Yang X Y and Zhang G J. Economic evaluation and decision method of oilfield development adjusting project. Petroleum Exploration and Development. 2006. 33(2): 246-249

Yu Q T and Li W X. Production stabilizing pattern for waterflooding reservoirs. Petroleum Geology and Oilfield Development in Daqing. 1998. 17(1): 20-25 (in Chinese)

Zhou L S and Zheng D P. Contract type and its change trend for international oil exploration and development. International Petroleum Economics. 2006. (9): 23-25 (in Chinese)

(Edited by Zhu Xiuqin) 